
\title{
$\begin{array}{ll}\text { Research Square } & \text { Preprints are preliminary reports that have not undergone peer review. } \\ \text { They should not be considered conclusive, used to inform clinical practice, } \\ \text { or referenced by the media as validated information. }\end{array}$
}

\section{Association between Prior Calcium Channel Blocker use and Mortality in Septic Patients: A Meta-Analysis of Cohort Studies}

Xianfei Ding

General Intensive Care Unit, The First Affiliated Hospital of Zhengzhou University, Henan Key Laboratory of Critical Care Medicine, Zhengzhou Key Laboratory of Sepsis, Zhengzhou 450052, China

Yuqing Cui

General Intensive Care Unit, The First Affiliated Hospital of Zhengzhou University, Henan Key Laboratory of Critical Care Medicine, Zhengzhou Key Laboratory of Sepsis, Zhengzhou 450052, China

\section{Yanhui Zhu}

General Intensive Care Unit, The First Affiliated Hospital of Zhengzhou University, Henan Key Laboratory of Critical Care Medicine, Zhengzhou Key Laboratory of Sepsis, Zhengzhou 450052, China

\section{Huoyan Liang}

General Intensive Care Unit, The First Affiliated Hospital of Zhengzhou University, Henan Key Laboratory of Critical Care Medicine, Zhengzhou Key Laboratory of Sepsis, Zhengzhou 450052, China

Dong Wang

General Intensive Care Unit, The First Affiliated Hospital of Zhengzhou University, Henan Key Laboratory of Critical Care Medicine, Zhengzhou Key Laboratory of Sepsis, Zhengzhou 450052, China

Lifeng Li

Biotherapy Center, The First Affiliated Hospital of Zhengzhou University, Zhengzhou 450052, China

Quancheng Kan

Department of Pharmacy, The First Affiliated Hospital of Zhengzhou University, Zhengzhou 450052, China

Lexin Wang

School of Biomedical Sciences, Charles Sturt University, WaggaWagga NSW2650, Australia

Tongwen Sun ( $\sim$ suntongwen@163.com)

the first affiliated hospital of zhengzhou university https://orcid.org/0000-0001-6536-3222

\section{Research}

Keywords: Calcium channel blocker, sepsis, septic shock, mortality, preadmission, systematic review, meta-analysis

Posted Date: July 15th, 2020

DOI: https://doi.org/10.21203/rs.3.rs-41244/v1

License: (ㅇ) This work is licensed under a Creative Commons Attribution 4.0 International License. Read Full License 


\section{Abstract}

Background: To comprehensively review the literature and synthesize evidence concerning the relationship between preadmission calcium channel blocker (CCB) use and mortality in patients with sepsis.

Methods: The MEDLINE, EMBASE, and Cochrane CENTRAL databases were searched from their inception to April 9, 2020. Cohort studies that related to prior CCB use in patients with sepsis were analysed. Pairs of reviewers independently screened studies, extracted data, and assessed the risk of bias. Two primary outcomes related to mortality, namely, 30-day mortality and 90-day mortality, were analysed; heterogeneity between studies was assessed using $R$ and was considered moderate if $R$ was equivalent to $50-75 \%$ and high if $P \geq 75 \%$. Fixed and random-effects models were used to calculate the pooled odds ratios (ORs) and $95 \%$ confidence intervals (Cls). The quality of outcomes was evaluated with the Newcastle-Ottawa Scale (NOS). Sensitivity analyses were performed to examine the robustness of the results.

Results: 552 potentially relevant studies were identified, and the full texts of 25 articles were reviewed. Ultimately, five cohort studies involving 280,982 patients were confirmed to have a low risk of bias and were included. Preadmission CCB use was associated with a significantly lower 30-day mortality in septic shock (OR, 0.61 [0.38-0.97]; $P=0.035 ; R=62.4 \%$ ), not in sepsis (OR, 0.83 [0.66-1.04]; $P=0.103 ; P=95.4 \%)$. Moreover, prior $C C B$ use could significantly reduce 30 -day mortality in sepsis (OR, $0.90[0.85-0.95] ; P<0.001 ; P=31.9 \%)$.

Conclusions: This meta-analysis suggests that preadmission CCB use is significantly associated with improving long-term prognosis of sepsis, and also shortterm survival of septic shock patients. This finding may provide an attractive direction for sepsis management.

\section{Background}

Sepsis is defined as a life-threatening disorder of organ function caused by dysregulated host responses to infection (1). Global epidemiological data suggest that sepsis is a major public health issue and remains a primary reason for mortality and critical illness; sepsis affects millions of people worldwide each year (2-4), and its incidence is not declining (5). Currently, the pathophysiological basis of sepsis is thought to involve a disorder of pro- and anti-inflammatory responses, which offers a new method for the treatment of this deadly disease (6). The prognosis is associated with not only the virulence of the pathogens but also the septic patient's age and coexisting diseases, such cardiovascular dysfunction (7).

Calcium channel blocker (CCB) is widely administered for cardiovascular disease therapy in conditions such as hypertension and ischaemic heart disease (8, 9). These drugs can inhibit $\mathrm{Ca}^{2+}$ channels in the myocardium and vascular smooth muscle cells, resulting in the inhibition of myocardial contractions, the pulse conduction system (anti-arrhythmias), and vasodilation (10). Cardiovascular disease is well known to be one of the most common coexisting conditions in septic patients and is independently related to an increased risk of death during hospitalization $(11,12)$. Sepsis is related to an overload of $\mathrm{Ca}^{2+}$ levels in many cell types (13) and can lead to disordered cellular processes, cytotoxicity or even cell death via a variety of mechanisms, such as metabolic manifestations, vascular smooth muscle tone dysregulation, mitochondrial dysfunction, nuclear damage, cytoskeletal breakage, production of nitric oxide and pro-inflammatory cytokines, and apoptosis $(14,15)$. However, CCB can restore such disrupted cellular processes to normal through calcium channel-dependent calcium ion homeostasis. Furthermore, CCB shows pleiotropic effects, such as antioxidant properties (16) \decreasing immunodepression and antiinflammatory activity (17), in sepsis. Therefore, CCB use may benefit patients with sepsis.

Recently, Wiewel et al (18) reported that previous CCB use had an obvious survival benefit compared with non-CCB use in patients with sepsis. However, several studies (19-21) have indicated that preadmission CCB use was not related to lower mortality in septic patients. In addition, Hsieh et al (21) reported that CCB had a decreased 30-day mortality in septic shock patients. But Roquetaillade et al (22) indicated that CCB using was not associated with lower mortality of septic shock patients. So the relationship between previous CCB use and prognosis is controversial in sepsis. Thus, a synthesis of obtainable data was performed to evaluate whether CCBs are helpful for reducing mortality in septic patients.

\section{Methods}

The study protocol is registered on the PROSPERO website (http://www.crd.york.ac.uk/PROSPERO) with the registration number CRD42019127112, which can be found online at https://www.crd.york.ac.uk/PROSPERO/display_record.php?RecordID=127112.

\section{Search Strategy}

The methodology followed the Observational Studies in Epidemiology guidelines for meta-analysis. A comprehensive literature search for cohort studies on CCB use and mortality of septic patients published from database inception to April 9, 2020, was performed using the MEDLINE (www.ncbi.nlm.nih.gov/pubmed), EMBASE (www.embase.com), and Cochrane CENTRAL (https://www.cochranelibrary.com/central) databases. A combination of MeSH/Emtree, title, abstract or keyword terms was used. The search terms were "calcium channel blockers", "calcium channel blocking agent", "calcium antagonist", "sepsis", and "septic shock". The detailed retrieval strategy can be seen in Supplemental Table 1. The search was restricted to English. Furthermore, we reviewed references of eligible articles to identify other potentially relevant studies. Literature searches were conducted independently by Xianfei Ding, Yuqing Cui and Yanhui Zhu.

\section{Eligibility Criteria}

Studies were considered eligible for inclusion in the meta-analysis if they met the following population, intervention, comparators, outcomes and study design (PICOS) criteria: 1) the population included adult septic patients, 2) the intervention involved preadmission use of CCB, 3 ) the comparison intervention 
consisted of non-CCB use, 4) the outcome was mortality, and 5) the study design was an observational cohort study. We excluded relevant studies that did not report outcome data. In addition, we also excluded literature for which full texts could not be searched and summarized and review articles.

\section{Study Selection and Data Extraction}

Xianfei Ding, Yuqing Cui and Yanhui Zhu independently screened the titles and/or abstracts of all retrieved studies to determine whether they potentially met the eligibility criteria and noted the cause for excluding each article. Key data explications were performed independently by Huoyan Liang and Lifeng Li. All disputes were settled by discussions with Dong Wang, Quancheng Kan and Lexin Wang. The following characteristics were extracted from all the included studies: first author, year (publication), country, study design, CCB and non-CCB use in patients with sepsis, sex composition of patients, study duration, and unadjusted or adjusted odds ratios (ORs) with $95 \%$ confidence intervals (Cls) for primary outcomes.

\section{Assessment of Risk of Bias}

The risk of bias of eligible studies was evaluated by the Newcastle-Ottawa Scale (NOS) for cohort studies (23). A maximum of nine points could be obtained: four points as the maximum for selection, two points as the maximum for design and analysis comparability, and three points as the maximum for assessment of outcomes. High-quality studies received a score $\geq 7$, whereas moderate- and low-quality studies received scores of $4-6$ and $\leq 4$, respectively.

\section{Statistical Analysis}

For binary data, we used ORs and their $95 \%$ Cls to estimate the effect sizes of our outcome of interest. The pooled ORs of the included studies were calculated by fixed-effects model with inverse-variance or a random-effects model with I-V heterogeneity method to generate forest plots. Heterogeneity among studies was evaluated by $P ; R$ values of $0-25 \%$ represented no heterogeneity, values of $25-50 \%$ represented mild heterogeneity, values of $50-75 \%$ represented moderate heterogeneity, and values of $75-100 \%$ represented high heterogeneity. A fixed-effects model was used to calculate pooled ORs when no or mild heterogeneity existed in the included studies; otherwise, a random-effects model was used. Begg's funnel plot (24) was constructed and Egger's linear regression (25) was performed to evaluate potential publication bias. Funnel plots were visually evaluated for dissymmetry. One-way sensitivity analysis was applied to evaluate the robustness of the results. All statistical analyses were performed by Stata 14.0 (College Station, Texas, 77845, USA, Serial number: 401406267051).

\section{Results}

\section{Study Selection}

The initial literature search yielded 552 potentially relevant publications, and 457 records remained after removing duplicates. We then excluded 432 records after preliminary title and abstract screening. After evaluating the full texts of the remaining 25 records, we identified 5 cohort studies (18-22) for inclusion in this meta-analysis (Fig. 1).

\section{Study Characteristics}

An in-depth detailed description of the 5 included studies is shown in Table 1. In total, 280,982 septic patients were included in this meta-analysis. All included studies were multi-centre cohort studies that involved septic patients who reported preadmission use of CCB (18-22). All included studies reported 30-day or 90-day mortality as the primary outcomes. We extracted the adjusted or propensity-matched ORs and $95 \%$ Cls from the primary outcome data. Otherwise, the data were calculated from the raw data from each included study. 
Table 1

Summary of identified studies

\begin{tabular}{|c|c|c|c|c|c|c|c|c|c|c|c|c|}
\hline \multirow[t]{2}{*}{ First Author } & \multirow[t]{2}{*}{ Year } & \multirow[t]{2}{*}{ Country } & \multirow{2}{*}{$\begin{array}{l}\text { Study } \\
\text { Design }\end{array}$} & \multirow{2}{*}{$\begin{array}{l}\text { Multi/ } \\
\text { Single } \\
\text { Centre }\end{array}$} & \multirow{2}{*}{$\begin{array}{l}\text { Number } \\
\text { of } \\
\text { Patients } \\
\text { in CCB } \\
\text { Use }\end{array}$} & \multirow{2}{*}{$\begin{array}{l}\text { Number } \\
\text { of } \\
\text { Patients } \\
\text { in non- } \\
\text { CCB } \\
\text { Use }\end{array}$} & \multirow{2}{*}{$\begin{array}{l}\text { Female/ } \\
\text { Male of } \\
\text { Patients in } \\
\text { CCB Use }\end{array}$} & \multirow{2}{*}{$\begin{array}{l}\text { Female/ } \\
\text { Male of } \\
\text { Patients in } \\
\text { non-CCB Use }\end{array}$} & \multirow{2}{*}{$\begin{array}{l}\text { Study } \\
\text { Duration }\end{array}$} & \multicolumn{3}{|c|}{ Primary Outcome (OR, 95} \\
\hline & & & & & & & & & & $\begin{array}{l}\text { 30-day } \\
\text { Mortality } \\
\text { in } \\
\text { sepsis" }\end{array}$ & $\begin{array}{l}\text { 30-day } \\
\text { Mortality } \\
\text { in septic } \\
\text { shock }\end{array}$ & $\begin{array}{l}9 \\
1 \\
\text { if } \\
\text { s }\end{array}$ \\
\hline $\begin{array}{l}\text { Wiewel } 2017 \\
\text { (18) }\end{array}$ & 2017 & Netherlands & PC & Multi & 197 & 863 & $79 / 118$ & $341 / 522$ & $\begin{array}{l}01 / 2011- \\
07 / 2013\end{array}$ & $\begin{array}{l}0.48 \\
(0.31- \\
0.74)\end{array}$ & $\begin{array}{l}0.31 \\
(0.14- \\
0.65)\end{array}$ & $\begin{array}{l}0 \\
(1 \\
0\end{array}$ \\
\hline $\begin{array}{l}\text { Lee } 2017 \\
(19)\end{array}$ & 2017 & Taiwan & $\mathrm{RC}$ & Multi & 19742 & 31336 & $8999 / 10743$ & $11904 / 19432$ & $\begin{array}{l}2000- \\
2011\end{array}$ & $\begin{array}{l}0.92 \\
(0.85- \\
0.99)\end{array}$ & NA & $\begin{array}{l}0 \\
(1 \\
0\end{array}$ \\
\hline $\begin{array}{l}\text { Kim } \\
(20)\end{array}$ & 2019 & $\begin{array}{l}\text { South } \\
\text { Korea }\end{array}$ & $\mathrm{RC}$ & Multi & 1287 & 3262 & $626 / 661$ & $1702 / 1560$ & $\begin{array}{l}2003- \\
2013\end{array}$ & $\begin{array}{l}0.83 \\
(0.72- \\
0.95)\end{array}$ & NA & $\begin{array}{l}0 \\
(1 \\
1\end{array}$ \\
\hline $\begin{array}{l}\text { Hsieh A } 2020 \\
(21)\end{array}$ & 2020 & Taiwan & $\mathrm{RC}$ & Multi & NA & NA & NA & NA & $\begin{array}{l}1999- \\
2013\end{array}$ & $\begin{array}{l}1.21 \\
(1.17- \\
1.26)^{*}\end{array}$ & NA & $\Lambda$ \\
\hline $\begin{array}{l}\text { Hsieh B } 2020 \\
(21)\end{array}$ & 2020 & Taiwan & $\mathrm{RC}$ & Multi & NA & NA & NA & NA & $\begin{array}{l}1999- \\
2013\end{array}$ & NA & $\begin{array}{l}0.64 \\
(0.53- \\
0.77)\end{array}$ & $\Lambda$ \\
\hline $\begin{array}{l}\text { Roquetaillade } \\
2020 \text { (22) }\end{array}$ & 2020 & French & $\mathrm{RC}$ & Multi & 103 & 632 & NA & NA & $\begin{array}{l}2008- \\
2016\end{array}$ & $\begin{array}{l}0.95 \\
(0.52- \\
1.74)\end{array}$ & $\begin{array}{l}0.95 \\
(0.52- \\
1.74)\end{array}$ & $\wedge$ \\
\hline
\end{tabular}

Abbreviations: PC prospective cohort, RC retrospective cohort, CCB calcium channel blockers, OR odds ratio, Cl confidence interval. \#, 30-day Mortality in seps included septic shock; *, 30-day Mortality in sepsis that not included septic shock.

\section{Risk of Bias Assessment}

The risk of bias assessment of the included studies is shown in Supplemental Table 2 . The five eligible studies (18-22) that had a point value $\geq 8$ were observational cohort studies and were considered to have a low risk of bias on the basis of the NOS.

\section{Effects of CCB on Septic Patients}

The results of the primary outcomes in this meta-analysis are shown in Figs. 2-4. A random-effects model was used to perform in this meta-analysis for 30day mortality due to high or moderate heterogeneity $(R=95.4 \%, 62.4 \%$, respectively), and fixed-effects model was used to perform in this meta-analysis for 90 day mortality due to mild heterogeneity $(R=31.9 \%)$ between studies. In the five included cohort studies, preadmission CCB use was associated with a significantly lower 30-day mortality in septic shock (OR, 0.61 [0.38-0.97]; $P=0.035 ; P=62.4 \%)$, not in sepsis $(\mathrm{OR}, 0.83$ [0.66-1.04]; $P=0.103 ; P=95.4 \%)$ (Figs. 2, 3). Moreover, prior CCB use was also associated with a significantly lower 90 -day mortality in sepsis $(0 \mathrm{R}, 0.90$ [0.85-0.95]; $P<0.001 ; R=31.9 \%)$ (Fig. 4).

\section{Sensitivity Analysis}

As the included studies were observational cohort studies with a low risk of bias (Supplemental Table 2), a sensitivity analysis of the methodological criteria was not conducted. A sensitivity analysis was conducted to evaluate the effect of any one study on the pooled ORs and $95 \%$ Cls by removing one individual study at a time. The sensitivity analysis findings indicated that the results were robust and reliable ((Supplemental Fig. 1-3).

\section{Publication Bias}

Because the number of included studies that reported the effects of CCB use on septic patients was small $(<10)$, we did not generate a funnel plot, as it may not have discovered publication bias (26).

\section{Discussion}

This meta-analysis involving 280,982 patients indicated that compared with non-CCB use, preadmission CCB use was related to reduced 90 -day mortality rate in patients with sepsis and 30-day mortality rate in patients with septic shock. To our knowledge, this is the first meta-analysis to explore and evaluate the relationship between preadmission CCB use and mortality in septic patients. These findings indicate that CCB administration is associated with significant effects on long-term prognosis of sepsis and also short-term survival of septic shock patients.

Currently, the outcome of preadmission CCB use on mortality of septic patients remains inconsistent $(18-22)$. Several animal studies $(27,28)$ have suggested that CCB could reduce mortality in endotoxaemic mouse models. And, verapamil improved the survival rate of dogs with endotoxin shock (29). However clinical researches are not consistent with this animal studies (19-21). This meta-analysis may provide supporting evidence that preadmission CCB use may be associated with decreased mortality among patients with sepsis. 
The potential mechanism underlying the association of CCB use and mortality in septic patients remains unclear. CCB may ameliorate cardiac dysfunction $(29,30)$ among septic survivors with cardiovascular complications (31). Several studies reported that CCB differentially inhibited the generation of proinflammatory factors, such as interleukin-12 (IL-12), interferon-gamma (IFN- $\gamma$ ) (28), and TNF-alpha (32) in sepsis. Additionally, CCB could inhibit nuclear transcription factor, NF-KB, and activated PI3K/Akt passage (33-36), which reducing LPS-induced acute inflammatory reaction (37). Moreover, CCB has been shown lower oxidative burst and inducible nitric oxide synthase (iNOS) protein expression to regulate inflammatory response (38), and ameliorates cellular injury and cardiac dysfunction. Most importantly, sepsis disrupts intracellular calcium homeostasis which lead to endothelial injury and destroyed subcelluar structures $(39,40)$. CCB, which is involved in targeting and blocking calcium ions overload $(41,42)$, can reduce intracellular $\mathrm{Ca}^{2+}$ levels and prevent cytotoxicity. As a result, CCB use with sepsis may lead to improved cardiovascular function and anti-inflammatory effect. It may be the explanation why CCB users had lower mortality among patients with sepsis. However, the relationship between CCB administration and sepsis prognosis needs clincial trial to further confirmation.

A meta-analysis was used to systematically and statistically analyse a variety of studies on the same topic. The summarized meta-analysis results present statistical heterogeneity when the difference among outcomes in the included individual studies is greater than expected. In the present meta-analysis, the assessment for risk of bias in eligible studies showed a low risk of bias; thus, methodological heterogeneity did not exist.

This meta-analysis has a few advantages. First, the sample of included septic patients was large, suggesting that the results may be stable. And the large population was sufficient to conduct propensity matching, which could reduce the effects of deviations and confounding variables between the CCB use and the non-CCB use group. Second, the NOS was used to assess risk of bias. The result indicated that this meta-analysis had a low risk of bias among the studies that met the inclusion criteria. Third, we extracted the adjusted or propensity-matched ORs and 95\% Cls to calculate the pooled ORs for the effect of CCB use on mortality in an unbiased manner. Fourth, the sensitivity analysis suggested that the results were robust and reliable.

However, this meta-analysis has several limitations. Although we conducted an overall search of the pertinent literature as far back as possible, only five studies were included; more researches may be needed to confirm this conclusion. Nevertheless, the robustness of the conclusion was supported by the sensitivity analysis. Besides, the studies included in this meta-analysis were only observational studies, not randomized controlled trials. The effectiveness of prior CCB treatment in severely ill patients need to be further elucidated in high-quality clinical trials. However, a certain limitation exists even if all the included cohort studies show a low risk of bias.

\section{Conclusions}

This is the first systematic review and meta-analysis to report the association between preadmission CCB use and mortality in septic patients. This metaanalysis suggests that preadmission CCB use is significantly associated with improving long-term prognosis of sepsis, and also short-term survival of septic shock patients. However, this finding should be evaluated in future RCT studies, as CCB remain an attractive intervention for future investigations aiming to improve sepsis-related mortality.

\section{Abbreviations}

CCB, calcium channel blocker; Cls, confidence intervals; NOS, Newcastle-Ottawa Scale; PICOS, population, intervention, comparators, outcomes and study design; LPS, lipopolysaccharide.

\section{Declarations}

\section{Consent for Publication}

Not applicable.

\section{Author Contributions}

All the authors contributed substantially to the work presented in this article. Dr. TWS, XFD, YQC and YHZ conceived the study. HYL and LFL contributed to the data interpretation. XFD YQC and YHZ contributed to the study protocol and wrote the article. DW, QCK and LXW settled the controversy. QCK, LXW, and TWS revised the article. All authors approved the final version submitted for publication. All authors agree to be accountable for all aspects of the work in ensuring that questions related to the accuracy or integrity of any part of the work are appropriately investigated and resolved.

\section{Acknowledgements}

We would like to thank the Chinese Evidence Based Medicine Center, West China Hospital, Sichuan University, for providing the Stata 14.0 statistical software.

\section{Availability of Data and Materials}

All data generated or analysed during this study are included in this published article [and its

supplementary information files].

\section{Ethical Approval and Consent to Participate}

Not applicable. 


\section{Funding}

This study was supported by the, Leading Talents Fund in Science and Technology Innovation in Henan Province (Grant No. 194200510017), Provincial Ministry Co-construction Project from Medical Scientific and Technological Research Program of Henan Province (Grant No. SBGJ2018020), the "51282" Project Leaders of Scientific and Technological Innovative Talents from Health and Family Planning Commission in Henan Province (2016-32), Science and Technology people-benefit project of Zhengzhou (2019KJHM0001)

\section{Author Details}

${ }^{1}$ General Intensive Care Unit, The First Affiliated Hospital of Zhengzhou University, Henan Key Laboratory of Critical Care Medicine, Zhengzhou Key Laboratory of Sepsis, Zhengzhou 450052, China. ${ }^{2}$ Biotherapy Center, The First Affiliated Hospital of Zhengzhou University, Zhengzhou 450052 , China. ${ }^{3}$ Department of Pharmacy, The First Affiliated Hospital of Zhengzhou University, Zhengzhou 450052, China. ${ }^{4}$ School of Biomedical Sciences, Charles Sturt University, WaggaWagga NSW2650, Australia.

\section{References}

1. Singer M, Deutschman CS, Seymour CW, Shankar-Hari M, Annane D, Bauer M, et al. The Third International Consensus Definitions for Sepsis and Septic Shock (Sepsis-3). Jama (2016) 315(8):801-10. Epub 2016/02/24. doi: 10.1001/jama.2016.0287. PubMed PMID: 26903338; PubMed Central PMCID: PMCPmc4968574.

2. Angus DC, Linde-Zwirble WT, Lidicker J, Clermont G, Carcillo J, Pinsky MR. Epidemiology of severe sepsis in the United States: analysis of incidence, outcome, and associated costs of care. Critical care medicine (2001) 29(7):1303-10. Epub 2001/07/11. PubMed PMID: 11445675.

3. Dellinger RP. Cardiovascular management of septic shock. Critical care medicine (2003) 31(3):946-55. Epub 2003/03/11. doi: 10.1097/01.ccm.0000057403.73299.a6. PubMed PMID: 12627010.

4. Rhodes A, Evans LE, Alhazzani W, Levy MM, Antonelli M, Ferrer R, et al. Surviving Sepsis Campaign: International Guidelines for Management of Sepsis and Septic Shock: 2016. Critical care medicine (2017) 45(3):486-552. Epub 2017/01/19. doi: 10.1097/ccm.0000000000002255. PubMed PMID: 28098591.

5. Gaieski DF, Edwards JM, Kallan MJ, Carr BG. Benchmarking the incidence and mortality of severe sepsis in the United States. Critical care medicine (2013) 41(5):1167-74. Epub 2013/02/28. doi: 10.1097/CCM.0b013e31827c09f8. PubMed PMID: 23442987.

6. Hotchkiss RS, Monneret G, Payen D. Sepsis-induced immunosuppression: from cellular dysfunctions to immunotherapy. Nature reviews Immunology (2013) 13(12):862-74. Epub 2013/11/16. doi: 10.1038/nri3552. PubMed PMID: 24232462; PubMed Central PMCID: PMCPmc4077177.

7. Angus DC, van der Poll T. Severe sepsis and septic shock. N Engl J Med (2013) 369(21):2063. Epub 2013/11/22. doi: 10.1056/NEJMc1312359. PubMed PMID: 24256390.

8. James PA, Oparil S, Carter BL, Cushman WC, Dennison-Himmelfarb C, Handler J, et al. 2014 evidence-based guideline for the management of high blood pressure in adults: report from the panel members appointed to the Eighth Joint National Committee (JNC 8). Jama (2014) 311(5):507-20. Epub 2013/12/20. doi: 10.1001/jama.2013.284427. PubMed PMID: 24352797.

9. Fihn SD, Gardin JM, Abrams J, Berra K, Blankenship JC, Dallas AP, et al. 2012 ACCF/AHA/ACP/AATS/PCNA/SCAI/STS Guideline for the diagnosis and management of patients with stable ischemic heart disease: a report of the American College of Cardiology Foundation/American Heart Association Task Force on Practice Guidelines, and the American College of Physicians, American Association for Thoracic Surgery, Preventive Cardiovascular Nurses Association, Society for Cardiovascular Angiography and Interventions, and Society of Thoracic Surgeons. Journal of the American College of Cardiology (2012) 60(24):e44-e164. Epub 2012/11/28. doi: 10.1016/j.jacc.2012.07.013. PubMed PMID: 23182125.

10. Sueta D, Tabata N, Hokimoto S. Clinical roles of calcium channel blockers in ischemic heart diseases. Hypertension research : official journal of the Japanese Society of Hypertension (2017) 40(5):423-8. Epub 2017/01/27. doi: 10.1038/hr.2016.183. PubMed PMID: 28123178.

11. Vincent JL, Rello J, Marshall J, Silva E, Anzueto A, Martin CD, et al. International study of the prevalence and outcomes of infection in intensive care units. Jama (2009) 302(21):2323-9. Epub 2009/12/03. doi: 10.1001/jama.2009.1754. PubMed PMID: 19952319.

12. Martin GS, Mannino DM, Eaton S, Moss M. The epidemiology of sepsis in the United States from 1979 through 2000. The New England journal of medicine (2003) 348(16):1546-54. Epub 2003/04/18. doi: 10.1056/NEJMoa022139. PubMed PMID: 12700374.

13. Hotchkiss RS, Karl IE. Calcium: a regulator of the inflammatory response in endotoxemia and sepsis. New horizons (Baltimore, Md) (1996) 4(1):58-71. Epub 1996/02/01. PubMed PMID: 8689276.

14. Dong Z, Saikumar P, Weinberg JM, Venkatachalam MA. Calcium in cell injury and death. Annual review of pathology (2006) 1:405-34. Epub 2007/11/28. doi: 10.1146/annurev.pathol.1.110304.100218. PubMed PMID: 18039121.

15. Clapham DE. Calcium signaling. Cell (2007) 131(6):1047-58. Epub 2007/12/18. doi: 10.1016/j.cell.2007.11.028. PubMed PMID: 18083096.

16. Mason RP, Mak IT, Walter MF, Tulenko TN, Mason PE. Antioxidant and cytoprotective activities of the calcium channel blocker mibefradil. Biochemical pharmacology (1998) 55(11):1843-52. Epub 1998/08/26. PubMed PMID: 9714303.

17. Das R, Burke T, Van Wagoner DR, Plow EF. L-type calcium channel blockers exert an antiinflammatory effect by suppressing expression of plasminogen receptors on macrophages. Circulation research (2009) 105(2):167-75. Epub 2009/06/13. doi: 10.1161/circresaha.109.200311. PubMed PMID: 19520970; PubMed Central PMCID: PMCPmc2745969.

18. Wiewel MA, van Vught LA, Scicluna BP, Hoogendijk AJ, Frencken JF, Zwinderman AH, et al. Prior Use of Calcium Channel Blockers Is Associated With Decreased Mortality in Critically III Patients With Sepsis: A Prospective Observational Study. Critical care medicine (2017) 45(3):454-63. Epub 2017/01/13. 
doi: 10.1097/ccm.0000000000002236. PubMed PMID: 28079604.

19. Lee CC, Lee MG, Lee WC, Lai CC, Chao CC, Hsu WH, et al. Preadmission Use of Calcium Channel Blocking Agents Is Associated With Improved Outcomes in Patients With Sepsis: A Population-Based Propensity Score-Matched Cohort Study. Critical care medicine (2017) 45(9):1500-8. Epub 2017/06/29. doi: 10.1097/ccm.0000000000002550. PubMed PMID: 28658023.

20. Kim J, Kim YA, Hwangbo B, Kim MJ, Cho H, Hwangbo Y, et al. Effect of Antihypertensive Medications on Sepsis-Related Outcomes: A Population-Based Cohort Study. Critical care medicine (2019). Epub 2019/01/29. doi: 10.1097/ccm.0000000000003654. PubMed PMID: 30688717.

21. Hsieh MS, How CK, Hsieh VC, Chen PC. Preadmission Antihypertensive Drug Use and Sepsis Outcome: Impact of Angiotensin-Converting Enzyme Inhibitors (ACEls) and Angiotensin Receptor Blockers (ARBs). Shock (Augusta, Ga) (2020) 53(4):407-15. Epub 2019/05/29. doi: 10.1097/shk.0000000000001382. PubMed PMID: 31135703.

22. de Roquetaillade C, Jamme M, Charpentier J, Chiche JD, Cariou A, Mira JP, et al. Hemodynamic Impact of Cardiovascular Antihypertensive Medications in Patients With Sepsis-Related Acute Circulatory Failure. Shock (Augusta, Ga) (2020). Epub 2020/02/23. doi: 10.1097/shk.0000000000001524. PubMed PMID: 32080062.

23. Wells GA, O'Connell D: The New-Ottawa Scale (NOS) for Assessing the Quality of Nonrandomized Studies in Meta-Analyses. Available at: [www.ohri.ca/programs/clinical_epidemiology/oxford.asp] (accessed 2014 October 16).

24. Begg CB, Mazumdar M. Operating characteristics of a rank correlation test for publication bias. Biometrics (1994) 50(4):1088-101. Epub 1994/12/01. PubMed PMID: 7786990.

25. Stuck AE, Rubenstein LZ, Wieland D. Bias in meta-analysis detected by a simple, graphical test. Asymmetry detected in funnel plot was probably due to true heterogeneity. BMJ (Clinical research ed) (1998) 316(7129):469; author reply 70-1. Epub 1998/03/11. PubMed PMID: 9492685; PubMed Central PMCID: PMCPmc2665578.

26. Lau J, loannidis JP, Terrin N, Schmid CH, Olkin I. The case of the misleading funnel plot. BMJ (Clinical research ed) (2006) 333(7568):597-600. Epub 2006/09/16. doi: 10.1136/bmj.333.7568.597. PubMed PMID: 16974018; PubMed Central PMCID: PMCPmc1570006.

27. Wyska E. Pretreatment with R(+)-verapamil significantly reduces mortality and cytokine expression in murine model of septic shock. International immunopharmacology (2009) 9(4):478-90. Epub 2009/03/18. PubMed PMID: 19291858.

28. Nemeth ZH, Hasko G, Szabo C, Salzman AL, Vizi ES. Calcium channel blockers and dantrolene differentially regulate the production of interleukin-12 and interferon-gamma in endotoxemic mice. Brain research bulletin (1998) 46(3):257-61. Epub 1998/07/17. PubMed PMID: 9667821.

29. Bosson S, Kuenzig M, Schwartz SI. Verapamil improves cardiac function and increases survival in canine E. coli endotoxin shock. Circulatory shock (1985) 16(3):307-16. Epub 1985/01/01. PubMed PMID: 3902273.

30. Zhu X, Bernecker OY, Manohar NS, Hajjar RJ, Hellman J, Ichinose F, et al. Increased leakage of sarcoplasmic reticulum Ca2+ contributes to abnormal myocyte Ca2+ handling and shortening in sepsis. Critical care medicine (2005) 33(3):598-604. Epub 2005/03/09. PubMed PMID: 15753753.

31. Ou SM, Chu H, Chao PW, Lee YJ, Kuo SC, Chen TJ, et al. Long-Term Mortality and Major Adverse Cardiovascular Events in Sepsis Survivors. A Nationwide Population-based Study. American journal of respiratory and critical care medicine (2016) 194(2):209-17. Epub 2016/01/26. doi: 10.1164/rccm.20151020230C. PubMed PMID: 26808711.

32. Li XQ, Cao W, Li T, Zeng AG, Hao LL, Zhang XN, et al. Amlodipine inhibits TNF-alpha production and attenuates cardiac dysfunction induced by lipopolysaccharide involving PI3K/Akt pathway. International immunopharmacology (2009) 9(9):1032-41. Epub 2009/04/28. doi: 10.1016/j.intimp.2009.04.010. PubMed PMID: 19393774.

33. Mustafa SB, Olson MS. Effects of calcium channel antagonists on LPS-induced hepatic iNOS expression. The American journal of physiology (1999) 277(2):G351-60. Epub 1999/08/13. doi: 10.1152/ajpgi.1999.277.2.G351. PubMed PMID: 10444449.

34. Hayashi M, Yamaji Y, Nakazato Y, Saruta T. The effects of calcium channel blockers on nuclear factor kappa B activation in the mesangium cells. Hypertension research : official journal of the Japanese Society of Hypertension (2000) 23(5):521-5. Epub 2000/10/04. PubMed PMID: 11016808.

35. Li G, Qi XP, Wu XY, Liu FK, Xu Z, Chen C, et al. Verapamil modulates LPS-induced cytokine production via inhibition of NF-kappa B activation in the liver. Inflammation research : official journal of the European Histamine Research Society [et al] (2006) 55(3):108-13. Epub 2006/05/05. doi: 10.1007/s00011005-0060-y. PubMed PMID: 16673153.

36. Hassoun SM, Marechal X, Montaigne D, Bouazza Y, Decoster B, Lancel S, et al. Prevention of endotoxin-induced sarcoplasmic reticulum calcium leak improves mitochondrial and myocardial dysfunction. Critical care medicine (2008) 36(9):2590-6. Epub 2008/08/06. doi: 10.1097/CCM.0b013e3181844276. PubMed PMID: 18679108.

37. Zhang WJ, Wei H, Hagen T, Frei B. Alpha-lipoic acid attenuates LPS-induced inflammatory responses by activating the phosphoinositide 3-kinase/Akt signaling pathway. Proceedings of the National Academy of Sciences of the United States of America (2007) 104(10):4077-82. Epub 2007/03/16. doi: 10.1073/pnas.0700305104. PubMed PMID: 17360480; PubMed Central PMCID: PMCPmc1805485.

38. Hotchkiss RS, Bowling WM, Karl IE, Osborne DF, Flye MW. Calcium antagonists inhibit oxidative burst and nitrite formation in lipopolysaccharidestimulated rat peritoneal macrophages. Shock (Augusta, Ga) (1997) 8(3):170-8. Epub 1997/09/26. PubMed PMID: 9377163.

39. Duchen MR. Mitochondria and calcium: from cell signalling to cell death. The Journal of physiology (2000) 529 Pt 1:57-68. Epub 2000/11/18. PubMed PMID: 11080251; PubMed Central PMCID: PMCPmc2270168.

40. Ding H, Cao XY, Ma XG, Zhou WJ. Endothelial cell injury with inflammatory cytokine and coagulation in patients with sepsis. World journal of emergency medicine (2013) 4(4):285-9. Epub 2013/01/01. doi: 10.5847/wjem.j.issn.issn.1920-8642.2013.04.008. PubMed PMID: 25215134; PubMed Central PMCID: PMCPmc4129900. 
41. Meldrum DR, Ayala A, Chaudry IH. Mechanism of diltiazem's immunomodulatory effects after hemorrhage and resuscitation. The American journal of physiology (1993) 265(2 Pt 1):C412-21. Epub 1993/08/01. doi: 10.1152/ajpcell.1993.265.2.C412. PubMed PMID: 8368271.

42. Song SK, Karl IE, Ackerman JJ, Hotchkiss RS. Increased intracellular Ca2t: a critical link in the pathophysiology of sepsis? Proceedings of the National Academy of Sciences of the United States of America (1993) 90(9):3933-7. Epub 1993/05/01. PubMed PMID: 8483913; PubMed Central PMCID: PMCPmc46420.

\section{Figures}
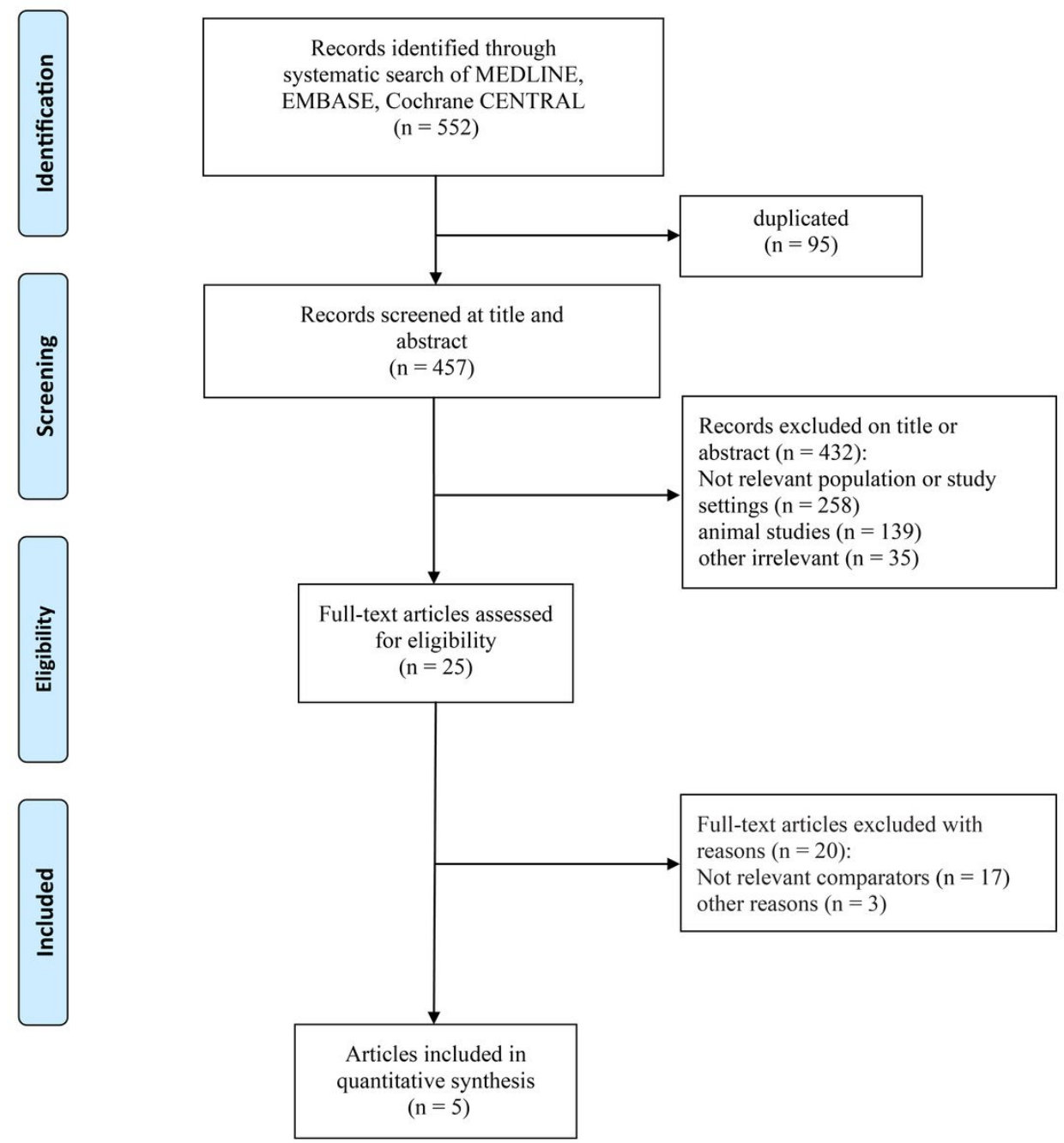

\section{Figure 1}

Flow chart of literature screening. 
ID

OR $(95 \% \mathrm{Cl})$

Weight

Hsieh 2020 B

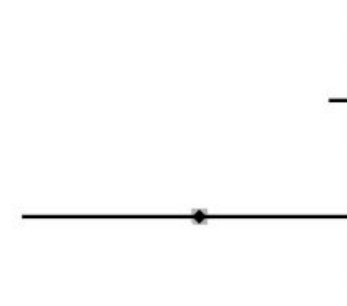

Roquetaillade 2020

Overall $(I-$ squared $=62.4 \%, p=0.070)$

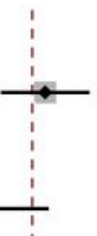

$0.64(0.53,0.77)$

49.25

Wiewel 2017

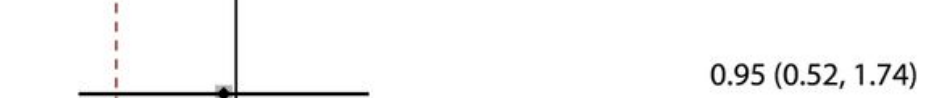

28.05

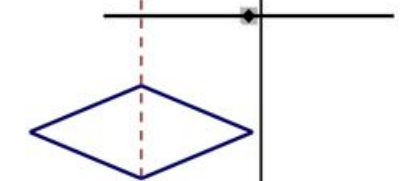

$0.61(0.38,0.97)$

100.00

NOTE: Weights are from random effects analysis

.148

1

\section{Favours Non-CCB}

Figure 2

Meta-analysis of overall pooled ORs with $95 \%$ Cls across studies for primary outcomes in patients with septic shock. Forest plot showing the significance of the relationship between preadmission use of CCBs and 30-day mortality in patients with septic shock according to the random-effects model. OR $=$ odds ratio, $\mathrm{CCB}=$ calcium channel blocker. 
ID

OR $(95 \% \mathrm{Cl})$ Weight

Lee 2017

Wiewel 2017

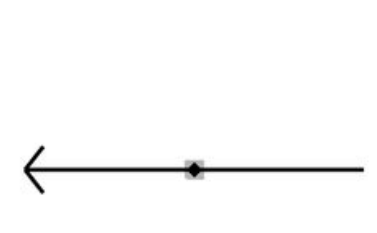

Kim 2019

Hsieh 2020 A

Hsieh 2020 B

Roquetaillade 2020

Overall $(I-$ squared $=95.4 \%, p=0.000)$

NOTE: Weights are from random effects analysis

.311

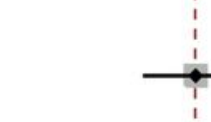

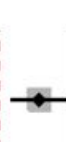

(1)
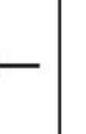

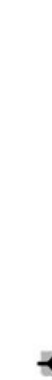

$0.92(0.85,0.99) \quad 20.65$

$0.48(0.31,0.74) \quad 11.88$

$0.83(0.73,0.95) \quad 19.63$

$1.21(1.16,1.26) \quad 20.97$

$0.64(0.53,0.77) \quad 18.49$

$0.95(0.52,1.74) \quad 8.38$

$0.83(0.66,1.04) \quad 100.00$

\section{Favours CCB}

\section{Favours Non-CCB}

\section{Figure 3}

Meta-analysis of overall pooled ORs with $95 \%$ Cls across studies for primary outcomes in patients with sepsis. Forest plot showing the significance of the relationship between preadmission use of CCBs and 30-day mortality in patients with sepsis according to the random-effects model. $\mathrm{OR}=$ odds ratio, $\mathrm{CCB}=$ calcium channel blocker. 
ID

OR $(95 \% \mathrm{Cl})$

Weight

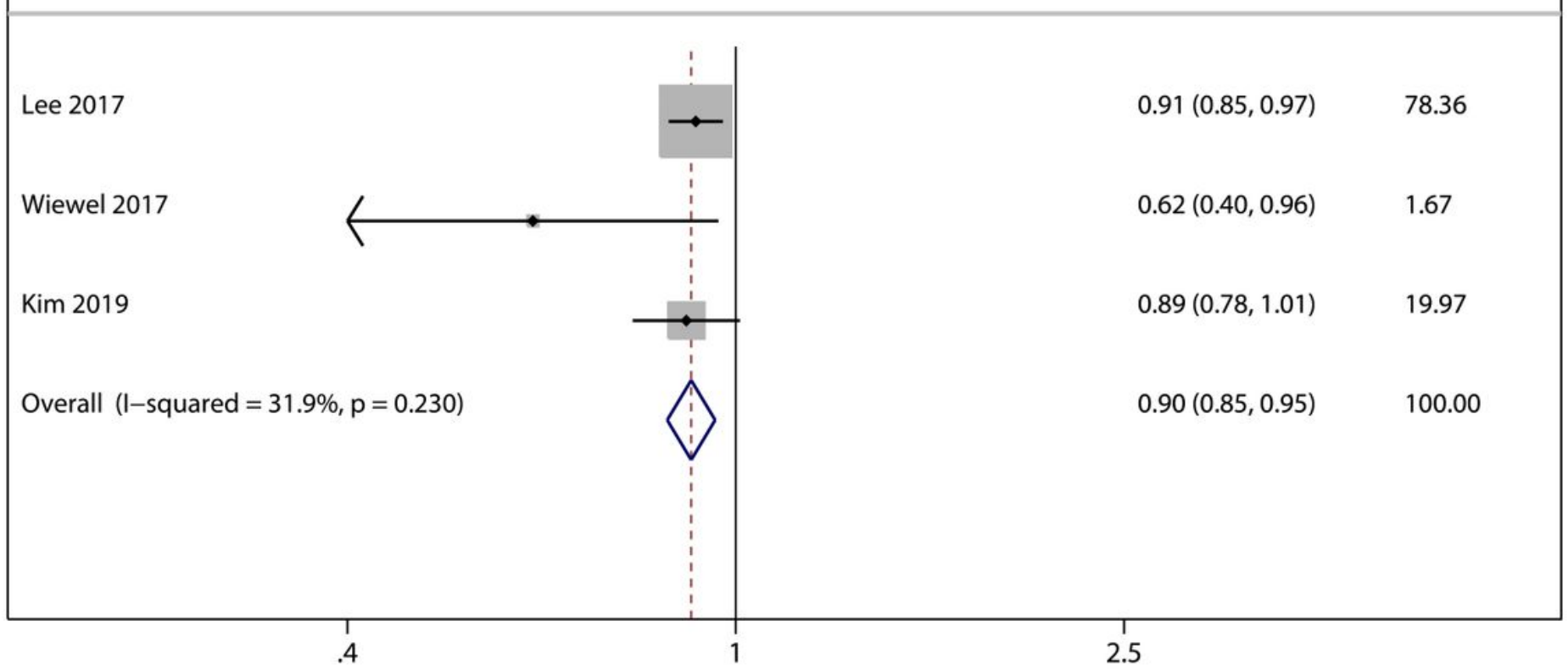

Favours CCB

Favours Non-CCB

\section{Figure 4}

Meta-analysis of overall pooled ORs with $95 \%$ Cls across studies for primary outcomes in patients with sepsis. Forest plot showing the significance of the relationship between preadmission use of CCBs and 90-day mortality in patients with sepsis according to the fixed-effects model. OR $=$ odds ratio, $\mathrm{CCB}=$ calcium channel blocker.

\section{Supplementary Files}

This is a list of supplementary files associated with this preprint. Click to download.

- SupplementalTable2.docx

- SupplementalTable1.docx

- SupplementalFig.3.tif

- SupplementalFig.2.tif

- SupplementalFig.1.tif 